\title{
Improving Outcomes for High-Risk Diabetics Using Information Systems
}

\author{
A. John Orzano, MD, MPH, Pamela Obman Strickland, PhD, Alfred F. Tallia, MD, MPH, \\ Shawna Hudson, PhD, Bijal Balasubramanian, MBBS, MPH, Paul A. Nutting, MD, MSPH, \\ and Benjamin F. Crabtree, PhD
}

Background: Diabetes care requires management of complex clinical information. We examine the relationship between diabetic outcomes and practices' use of information.

Methods: We performed a cross-sectional, secondary analysis of baseline data from 50 community primary care practices participating in a practice improvement project. Medical record review assessed clinical targets for diabetes $\left(\mathrm{HbA}_{1 \mathrm{c}} \leq 8, \mathrm{LDL} \leq 100, \mathrm{BP} \leq 130 / 85\right)$. Practices' use of information was derived from clinician responses to a survey on their use of clinical information systems for patient identification and tracking. Hierarchical linear modeling examined relationships between patient outcomes and practice use of information, controlling for patient level covariates (age, gender, hypertension, and cardiovascular comorbidities) and practice level covariates (solo/group, and electronic health record [EHR] presence).

Results: Practices' use of identification and tracking systems significantly $(P<.007$ and 0.002$)$ increased odds of achieving diabetes care targets (odds ratio [OR] 1.23 95\%, confidence interval [CI] 1.06 to 1.44 , and OR $1.3295 \%$ CI 1.11 to 1.59 ). For diabetic patients with hypertension, odds of hypertension control were higher with higher use of tracking systems $(\mathrm{OR}=1.52, P=.0017)$ and reflected similar trend with higher use of identification systems $(O R=1.28, P=.1349)$. EHR presence was not associated with attainment of clinical targets.

Conclusions: Use of relatively simple systems to identify and track patient information can improve diabetic care outcomes. Practices making investments in an EHR must recognize that this technology alone is not sufficient for achieving desirable clinical outcomes. Researchers must explore the interrelationships of organizational factors necessary for successful information use. (J Am Board Fam Med 2007;20:245-251.)

Although a gap exists between guidelines and practice in diabetic patient care, ${ }^{1}$ increasing evidence suggests guideline application efforts require prioritization and customization to those patients who are most at risk from complications and who would

This article was externally peer reviewed.

Submitted 29 October 2006; revised 2 February 2007; accepted 12 February 2007.

From the Department of Family Medicine/Research Division, University of Medicine and Dentistry of New JerseyRobert Wood Johnson Medical School, Somerset, NJ (AJO, AFT, SH, BB, BFC); Cancer Institute of New Jersey, New Brunswick, NJ (AJO, AFT, SH, BFC); University of Medicine and Dentistry of New Jersey-School of Public Health and Department of Biometrics, Somerset, NJ (POS); and Center for Research Strategies, Denver, CO (BFC).

Funding: This work was supported by Agency for Healthcare Research and Quality grant K08 HS14018 and National Heart, Lung, and Blood Institute grant R01 HL070800.

Conflicts of interest: none declared.

Corresponding author: A. John Orzano, MD, MPH, Department of Family Medicine/Research Division, University of Medicine and Dentistry of New Jersey-Robert Wood Johnson Medical School, 1 World's Fair Drive, Somerset, NJ 08873 (E-mail: orzanoaj@umdnj.edu). benefit most from interventions. ${ }^{2}$ Consequently both practitioners and researchers are challenged to apply interventions to minimize resources and maximize results.

Primary care of diabetic patients requires access to and management of complex clinical information. Primary care practices deal with multiple competing demands, ${ }^{3}$ and the ability to identify at risk patients ${ }^{4}$ and track their management and prevention parameters are important information needs. ${ }^{5}$ Therefore, clinical information systems should help focus scarce practice resources on patients most at risk. However, the ability to meet these information needs in primary care practices is increasingly challenged by a host of factors, including rapid scientific advances, ${ }^{6}$ financial pressures to increase patient throughput ${ }^{7}$ and limit expenditures ${ }^{8}$ and discontinuity of care caused by patient mobility, ${ }^{9}$ insurance turnover, ${ }^{10}$ and the provision of care through multiple providers. ${ }^{11}$ Rather than being used as excuses, these challenges actually 
provide reasons for better information systems. Information cannot be retained in the memory of a single clinician or buried in longitudinal progress notes and at the same time be reliably available for decision making. Reconciling information needs with practice resources remains a challenge.

Recent models for improving quality ${ }^{12-14}$ advocate expanding interventions beyond clinicians and effecting change in the practice as an organization. Although some models have advocated considerable investment in infrastructure such as EHR, ${ }^{15,16}$ and personnel, ${ }^{14}$ a model for change and improvement developed by our research team focuses on the importance of practice work relationships and incorporates the concept of interdependent practice organizational attributes. ${ }^{17}$ One organizational attribute is the practice's capacity to access and use information to deliver quality care. ${ }^{18}$ The use of clinical information systems is one aspect of this capacity hypothesized as supporting individual and organizational decision making. ${ }^{19}$ Whether electronic or paper, these information systems identify at-risk patients and track relevant prevention and treatment parameters.

In this study, we empirically test 3 hypotheses, which were developed a priori: Hypothesis 1 (H1), the use of clinical information systems favorably impacts patient-level measures of diabetes assessment, treatment and achievement of targets among all diabetic patients; $\mathrm{H} 2$, information use favorably impacts patient level measures particularly in diabetics with comorbidities; and $\mathrm{H} 3$, information use favorably impacts hypertensive control in diabetics with hypertension. $\mathrm{H} 2$ and $\mathrm{H} 3$ examine practice information use for those patients with more complex decision making information needs, at greater risk and who would benefit the most from intervention.

\section{Methods}

\section{Study Design and Data Collection}

This secondary analysis focused on cross-sectional data from 56 group and solo New Jersey and Pennsylvania family medicine practices participating in ULTRA (Using Learning Teams for Reflective Adaptation), an intervention study ${ }^{20}$ aimed at improving adherence to guidelines for multiple conditions. Six practices were eliminated because of insufficient data $(0 \%$ response rate on clinician surveys). Chart auditors retrospectively assessed each practice's adherence to diabetes guidelines in up to 20 patients randomly selected from a list of all adult patients within the past year treated for diabetes (ICD-9 codes 250.00-250.91). Some practices had fewer than 20 patients that could be identified using ICD-9 codes. Individual and interauditor reliability was assessed several times throughout the course of data collection. Clinicians (physicians, NPs, PAs) completed a 20-minute self-administered organizational survey that included items intended to assess their use of clinical information systems. This study was approved by the University of Medicine and Dentistry of New Jersey institutional review board.

\section{Measures}

The primary outcome measure was adherence to diabetic care guidelines developed by research team by adapting clinical practice guidelines of the American Diabetes Association. ${ }^{21}$ These guidelines can comprise 3 components: assessment, treatment, and attainment of targets. Individual items that are included in each of these components are described in Table 1. These analyses focused on the effect of information system use on the attainment of quality comprehensive care for diabetes as measured by each guideline component rather than individual items of the guideline components.

Main independent variables were use of clinical information systems and presence of comorbid diseases. The use of clinical information systems was divided into 2 categories: 1) Identification of patients (assessed by 2 questions: "How often do you use a patient registry to track patients with specific conditions?" and "How often do you use a health risk assessment protocol or questionnaire to identify patients who may benefit from counseling or other interventions targeting 4 health behaviors [tobacco use, alcohol use, eating habits/patterns, physical activity]?”); and 2) tracking systems (assessed by 4 questions: "How often do use computerized clinician reminders?", "How often do you use checklists/flowsheets in general?", "How often do you use checklists/flowsheets for chronic disease?", and "How often do you use risk factor chart stickers?"). Clinicians rated each item on a 5 -point Likert scale (1, never; 5, always). For each independent variable category, clinicians were assigned the maximum value of all items comprising that category. For instance, of the 2 patient identification items, a clinician was assigned a score of 5 if he or 


\begin{tabular}{|c|c|}
\hline Components and Items & Adherence Measures \\
\hline $\begin{array}{l}\text { Assessment } \\
\mathrm{HbA}_{1 \mathrm{c}} \text { in the past } 6 \text { months } \\
\text { LDL in the past } 12 \text { months } \\
\text { Microalbumin in the past } 12 \text { months } \\
\text { BP at every visit } \\
\text { Smoking status ever assessed }\end{array}$ & $\begin{array}{l}\text { Assessment } \\
\text { Acceptable: at least } 3 \text { of the items completed }\end{array}$ \\
\hline $\begin{array}{l}\text { Treatment } \\
\mathrm{HbA}_{1 \mathrm{c}} \leq 8 \% \text { or }>8 \% \text { and on a hypoglycemic agent } \\
\mathrm{LDL} \leq 100 \text { or }>100 \text { and on a lipid-lowering agent } \\
\mathrm{BP} \leq 130 / 85 \text { or }>130 / 85 \text { and on an antihypertensive } \\
\text { Urine microalbumin }>30 \text { and on angiotensin-converting enzyme } \\
\text { inhibitor or angiotensin-receptor blocker }\end{array}$ & $\begin{array}{l}\text { Treatment } \\
\text { Acceptable: all items adhered to }\end{array}$ \\
\hline $\begin{array}{l}\text { Target } \\
\qquad \mathrm{HbA}_{1 \mathrm{c}} \leq 7 \% \\
\mathrm{LDL} \leq \mathrm{t} 00 \\
\mathrm{BP} \leq 130 / 85\end{array}$ & $\begin{array}{l}\text { Target } \\
\text { Acceptable: all values achieved } \\
\text { Partial: any } 2 \text { values achieved }\end{array}$ \\
\hline
\end{tabular}

she scored 4 on one item and 5 on the other. A practice's overall score was the average of clinicians' maximums. Maximums were used to assess clinicians' use of any of these systems and reflects the variety of information systems (eg, computer or paper) that exist among practices and clinicians within practices. Moreover, using averages didn't substantially alter the findings.

Two comorbid conditions were recorded from each chart, if present: hypertension and heart disease (coronary artery bypass graft, stent, myocardial infarction, angina, congestive heart failure). Additional patient level covariates included age and gender. Other patient level variables were not available through chart audit. Practice level covariates included solo or not and presence of EHR.

\section{Analysis}

Hierarchical logistic regression ${ }^{22}$ assessed the association between a practice's use of clinical information systems and patient-level measures of diabetes assessment, treatment and achievement of targets (H1). Specifically, generalized estimating equations, via the GENMOD procedure within SAS, ${ }^{23}$ estimated $\log$-odds adherence as a function of practice- and patient-level covariates. Standard errors for estimates were adjusted to account for correlation between patients within a practice through use of a working correlation matrix with an exchangeable structure. Type III score tests were used to evaluate main effects of identification and tracking systems.
These analyses were stratified by comorbidity. We hypothesized (H2) that information systems would favorably affect outcomes in diabetic patients with comorbidities because of more complex decision-making information needs.

Additional analyses to explore the thesis around more complex decision-making information needs looked at patients with both diabetes and hypertension. Rather than examine the effect of hypertension as a comorbid condition on the impact of diabetic care information systems, this analysis explored the hypothesis: Information systems would effect coexisting condition outcomes (H3).

\section{Results}

\section{Description of Practices, Patients, and Use of Clinical Information Systems}

Overall, $69.5 \%$ of the clinicians returned a completed organizational survey that provided information on their use of clinical information systems. For individual practices, response rates ranged from $25 \%$ to $100 \%$, with an average practice response rate of $73.8 \%$ for the 50 practices.

Of 50 practices, 9 were solo and 13 used EHRs. Practices differed with respect to the Identification of Patients scale (mean $=3.24, \mathrm{SD}=0.86$ ), with 10 falling between 4.0 and 5.0 and, at the low end, 2 in the range from 1.0 to 1.9. The scale for Tracking Systems demonstrated similar differences between practices (mean $=3.54, \mathrm{SD}=0.95)$, with 24 practices scoring between 4.0 and 5.0 and 4 between 1.0 and 1.9 . 
Table 2. OR, $P$ values, and 95\% CI for the effect of Clinical Information Systems Use (Measured as an Average of Clinician Usage Scores on Adherence to Diabetes Care Guidelines, Controlling for Patient- and Practice-Level Covariates)*

\begin{tabular}{lccc}
\hline & OR & Value of $P$ & CI for OR \\
\hline Identification of Patients & & & \\
$\quad$ Assessment & $0.79+$ & 0.207 & $0.55,1.14$ \\
Treatment & 0.74 & 0.098 & $0.87,1.06$ \\
Target (2 of 3) & 1.23 & 0.007 & $1.06,1.44$ \\
$\quad$ Target (all 3) & 1.22 & 0.192 & $0.91,1.63$ \\
Tracking Systems & & & \\
Assessment & 1.10 & 0.567 & $0.80,1.51$ \\
Treatment & 1.15 & 0.330 & $0.87,1.51$ \\
Target (2 of 3) & 1.32 & 0.002 & $1.11,1.59$ \\
Target (all 3) & 1.28 & 0.100 & $0.95,1.73$ \\
\hline
\end{tabular}

*Patient level covariates included age, gender, whether the person had a heart condition and/or hypertension. Practice level covariates included whether the practice uses an EMR and whether the practice is a solo or group practice.

†For a 1-point increase in the score for "identification of patients" (on a scale of 1 to 5), the odds of appropriate assessment decrease by $21 \%$.

Of the 883 patients eligible for inclusion, $49 \%$ were male and the mean age was 60.1 years $(\mathrm{SD}=$ 14.3). A total of $16.0 \%$ of the patients had heart disease and $62.5 \%$ were diagnosed with hypertension. Across the 50 practices, mean rates of adherence for assessment, treatment, achievement of 2 of 3 targets and achievement of all 3 targets were $55 \%$ $(\mathrm{SD}=25 \%), 64 \%(\mathrm{SD}=19 \%), 49 \%(\mathrm{SD}=14 \%)$, and $11 \%(\mathrm{SD}=9 \%)$, respectively.

(H1) Use of Clinical Information Systems Favorably Impacts Patient-Level Measures of Diabetes Assessment, Treatment and Achievement of Targets Among All Diabetic Patients

Table 2 summarizes the main effects of the use of clinical information systems on adherence to guidelines. The use of identification systems, whether through health risk assessment protocols or a registry was found to significantly improve the partial achievement of targets (at least 2 of 3 targets, $P=$ .007 ), but not adherence to assessment or treatment guidelines. Subsequent analyses of individual targets demonstrated that this significance was largely due to achievement of blood pressure targets $(P=$ .0420).

The use of tracking systems, including computerized clinician reminders, checklists/flowcharts in general, checklists/flowcharts for chronic disease or risk factor chart stickers, also significantly increased the odds of partial achievement of targets $(P=$ .002) for patients with diabetes, but not the odds of appropriate assessment or treatment. Subsequent analyses of individual targets demonstrated that this significance was due to both achievement of blood pressure as well as LDL targets $(P=.0027$ and 0.0420 , respectively).

(H2) Use of Clinical Information Systems Favorably Impacts Patient Level Diabetes Measures

Particularly in Diabetic Patients with Comorbidities

Table 3 presents the odds ratios and $P$ values describing the effectiveness of each information system component at improving diabetes care among patients with hypertension or a heart condition or neither. Use of tracking systems was associated with increased odds of achievement of diabetes targets (both partial and full, $P=.010$ and 0.027 ) in patients with hypertension. For example, patients' odds of achievement of 2 of 3 targets were increased by $23 \%$ in practices in which the usage of patient identification systems was increased by 1 point (on a scale of 1 to 5 ).

Identification systems was also associated with increased odds of achievement of all 3 targets $(P=$ .029). A negative relationship was found between the use of identification systems and achievement of treatment guidelines $(P=.015)$ in patients with hypertension, although this relationship did not carry over into achievement of targets $(P=.284$ and 0.651).

\section{(H3) Use of Clinical Information Systems Favorably Impacts Hypertensive Control in Diabetics with Hypertension}

For patients with diabetes and hypertension, the odds of achieving target blood pressure were higher if the practice had more frequent use of tracking systems $(\mathrm{OR}=1.52, P=.0017)$ and reflected a similar trend with more frequent use of identification systems $(\mathrm{OR}=1.28, P=.1349)$.

\section{Discussion}

This study suggests that the use of relatively simple systems to identify and track patient information may improve diabetic care outcomes. Furthermore the effect was slightly stronger in the management 
Table 3. OR and $P$ Values Describing the Effect of Clinical Information Systems Use (Measured as an Average of Clinician Usage Scores) on Adherence to Diabetes Care Guidelines Among Patients With and Without Comorbid Conditions*

\begin{tabular}{|c|c|c|c|c|c|}
\hline & & \multicolumn{2}{|c|}{ Identification of Patients } & \multicolumn{2}{|c|}{ Tracking Systems } \\
\hline & & OR & Value of $P$ & OR & Value of $P$ \\
\hline \multirow[t]{3}{*}{ Assessment } & Heart Condition & $1.08+$ & 0.768 & 1.02 & 0.966 \\
\hline & Hypertension & 0.80 & 0.247 & 0.97 & 0.865 \\
\hline & Neither & 0.70 & 0.188 & 1.50 & $0.030 \neq$ \\
\hline \multirow[t]{3}{*}{ Treatment } & Heart Condition & 1.12 & 0.925 & 1.27 & 0.468 \\
\hline & Hypertension & 0.62 & $0.015 \S$ & 1.27 & $0.095 \ddagger$ \\
\hline & Neither & 0.78 & 0.368 & 1.17 & 0.466 \\
\hline \multirow[t]{3}{*}{ Target (2 of 3$)$} & Heart Condition & 1.34 & 0.292 & 1.12 & 0.481 \\
\hline & Hypertension & 1.13 & 0.284 & 1.42 & $0.010 \ddagger$ \\
\hline & Neither & 1.44 & $0.049 \ddagger$ & 1.14 & 0.274 \\
\hline \multirow[t]{3}{*}{ Target (all 3) } & Heart Condition & 2.30 & $0.029 \ddagger$ & 1.12 & 0.720 \\
\hline & Hypertension & 1.08 & 0.651 & 1.46 & $0.027 \ddagger$ \\
\hline & Neither & 1.39 & 0.201 & 1.25 & 0.305 \\
\hline
\end{tabular}

*Patient-level covariates included age and gender; practice-level covariates included whether the practice uses an EMR and whether the practice is a solo or group practice.

†Among patients with a heart condition, the odds of appropriate assessment according to guidelines increased by $8 \%$ with a 1 -point increase (on a scale of 1 to 5) for use of patient identification systems. (Not significant, $P=0.768$.)

$\ddagger$ Use of information system component associated with improved diabetes care.

$\S U$ se of information system component associated with decreased diabetes care.

of higher risk diabetic patients with hypertension or heart condition as comorbid conditions. Furthermore, among diabetic patients with coexisting hypertension, both identification and tracking systems favorably impacted hypertensive control. Providing care to these high-risk diabetic patients requires management of more complex information for decision making. In other organizational settings the access to information and in particular the use of information impacts performance through influencing work relationships for better decision making, learning, and task execution. ${ }^{24,25}$

Although we found no relationship with measures of assessment and treatment (process measures), a finding reflected also in mixed results from other studies, ${ }^{26,27}$ outcomes still remain most relevant. If the current conceptualization of processes and outcomes is not consistent with real-world practices, perhaps exploring further the capacity of a practice to access and use information can enhance our understanding of these presumed connections and assist in implementing guidelines.

Although drawn from cross-sectional data, our results suggest as in other studies ${ }^{28-30}$ that relatively modest practice efforts might be associated with significantly improved outcomes of diabetes care. Our findings are particular salient because the majority of primary care practices are smaller, independent practices ${ }^{31,32}$ such as those represented in our study.

Interestingly, this study also suggests that practices can achieve better outcomes without reliance on highly expensive office systems for patient identification and tracking. Our results are consistent with previous reports, ${ }^{33-37}$ and should caution the rush to EHR implementation as an automatic fix for quality-of-care issues. In fact combining results from this analysis and another ${ }^{34}$ suggest that practices with identification systems (if used in conjunction with an EHR) seem to do better on patient care despite the EHR, rather than because of any advantage provided by the EHR. EHR design and implementation requires specific attention to how information is accessed and used for identification and tracking chronic care patients. Whether implementing more technologically sophisticated or relatively simpler information systems, practitioner and research attention should be extended to reasons why some practices not only choose a particular system or combination but also why the variation in their effective incorporation. As in other organizational settings, paying attention to social factors like the characteristics of work relationships may be salient. ${ }^{38,39}$ 
Strengths of this study include participation by smaller community practices that are independent or owned by loosely organized health systems, and using process and outcome measures for diabetes. There are also limitations. Survey questions regarding information system usage were not specific to diabetes care and, thus, the positive associations with diabetes care need confirmation. However, diabetes is highly prevalent in practices, and one would expect diabetes to have been considered in responses to the survey. Further, clinician self-report on the extent of use of information systems may have been less accurate than, for example, direct observation of that use.

Finally, one finding remains unexplained. Those practices with high use of identification systems seemed to reflect poorer treatment adherence in patients with hypertension. However, even these patients in the higher-use group had better scores (treated better) than those patients without any comorbid condition, and we did not see this negative effect translate into achieving targets.

Overall, for practicing clinicians, these results suggest that efforts summarizing patient specific clinical information are not misplaced, and that expensive technology is not always necessary for achieving good outcomes. For researchers, the conceptualization of practices' capacity to access and use information needs refinement to expand the framework beyond clinical information systems. Acquiring, distributing, and using the best clinical information at the point of service are no longer sufficient to achieving successful outcomes. ${ }^{40-42}$ Practices must also incorporate processes to share and develop ${ }^{40,41}$ information or knowledge to impact care by enhancing organizational as well as individual decision making and learning. Knowledge Management ${ }^{24,43,44}$ and related disciplines and practices such as organizational learning, organizational knowledge, and learning organization $^{19,45}$ may provide fruitful exploration. In addition, this refinement must also explore the interdependencies of this capacity with other organizational attributes such as leadership, motivation, and office relationships. ${ }^{17,18}$ Such an integrative framework may better inform future research on how diabetes care and primary care delivery generally can be improved in the context of a myriad of competing demands, limited practice resources, and a misaligned health system.

\section{References}

1. Saydah SH, Fradkin J, Cowie CC. Poor control of risk factors for vascular disease among adults with previously diagnosed diabetes. JAMA 2004;291:335-42.

2. O'Connor PJ. Setting evidence-based priorities for diabetes care improvement. Int J Qual Health Care 2003;15:283-5.

3. Jaen CR, Stange KC, Nutting PA. Competing demands of primary care: a model for the delivery of clinical preventive services. J Fam Pract 1994;38: 166-71.

4. Bodenheimer T, Wagner EH, Grumbach K. Improving primary care for patients with chronic illness. JAMA 2002;288:1775-9.

5. Peterson KA. Primary care of type 2 diabetes. The challenges of emerging evidence. J Fam Pract 1998; 47(5 Suppl):S11-2.

6. Peterson KA, Spann SJ. Primary care for patients with type 2 diabetes. Moving beyond hyperglycemia. J Fam Pract 1998;47(5 Suppl):S63-4.

7. Grumbach K. Primary care in the United States: the best of times, the worst of times. $\mathrm{N}$ Engl J Med 1999;341:2008-10.

8. Martin JC, Avant RF, Bowman MA, et al. The Future of Family Medicine: a collaborative project of the family medicine community. Ann Fam Med 2004;2 Suppl 1:S3-32.

9. Graham R, Roberts R, Ostergaard D, Kahn N, Pugno P, Green L. Family practice in the United States: a status report. JAMA 2002;288:1097-101.

10. Kikano GE, Flocke SA, Gotler RS, Stange KC. 'My insurance changed': the negative effects of forced discontinuity of care. Fam Pract Manag 2000;7:44-5.

11. Larson EB, Grumbach K, Roberts KB. The future of generalism in medicine. Ann Intern Med 2005;142: 689-90.

12. O'Connor PJ, Solberg LI, Baird M. The future of primary care: the enhanced primary care model. J Fam Pract 1998;47:62-7.

13. IOM Committee on Quality of Health Care in America. Exploring Innovation and Quality Improvement in Health Care Micro-Systems. Washington, DC: National Academy Press; 2000.

14. Bodenheimer T, Wagner EH, Grumbach K. Improving primary care for patients with chronic illness: the chronic care model, Part 2. JAMA 2002; 288:1909-14.

15. Bodenheimer T, Grumbach K. Electronic technology: a spark to revitalize primary care? JAMA 2003; 290:259-64.

16. Grumbach K, Bodenheimer T. A primary care home for Americans: putting the house in order. JAMA 2002;288:889-93.

17. Cohen D, McDaniel R, Crabtree B, et al. A practice change model for quality improvement in primary care practice. J Healthc Manag 2004;49:155-68.

18. Orzano AJ, Tallia AF, Nutting PA, Scott-Cawiezell 
J, Crabtree BF. Are attributes of organizational performance in large health care organizations relevant in primary care practices? Health Care Manage Rev 2006;31:2-10.

19. Easterby-Smith M, Lyles M. Handbook of organizational learning and knowledge management. Malden, MA: Blackwell; 2005.

20. Stroebel CK, McDaniel RR, Jr, Crabtree BF, Miller WL, Nutting PA, Stange KC. How complexity science can inform a reflective process for improvement in primary care practices. Jt Comm J Qual Patient Saf 2005;31:438-46.

21. American Diabetes Association Clinical Practice Recommendations. Diabetes Care 2001;24(Suppl 1): S1-133.

22. Raudenbush S, Bryk A. Hierarchical linear models: applications and data analysis methods. Thousand Oaks, CA: Sage Publications; 2002.

23. SAS Institute Inc. SAS/STAT user's guide, version 8. Cary, NC: SAS Institute Inc.; 1999.

24. Davenport T, Prusak L. Working knowledge: how organizations manage what they know. Boston: Harvard Business School Press; 1998.

25. Pfeffer J. The knowing-doing gap: how smart companies turn knowledge into action. Boston: Harvard Business School Press; 2000.

26. IOM. Crossing the quality chasm: a new health system for the 21st century. Washington DC: National Academy Press; 2001.

27. Renders CM, Valk GD, Griffin SJ, Wagner EH, Eijk Van JT, Assendelft WJ. Interventions to improve the management of diabetes in primary care, outpatient, and community settings: a systematic review. Diabetes Care 2001;24:1821-33.

28. Sperl-Hillen JM, Solberg LI, Hroscikoski MC, Crain AL, Engebretson KI, O'Connor PJ. Do all components of the chronic care model contribute equally to quality improvement? Jt Comm J Qual Saf 2004;30:303-9.

29. Solberg LI, Hroscikoski MC, Sperl-Hillen JM, Harper PG, Crabtree BF. Transforming medical care: case study of an exemplary, small medical group. Ann Fam Med 2006;4:109-16.

30. Nutting $P$, Dickinson $W$, Dickinson L, et al. Use of chronic care model elements is associated with higher quality care for diabetes. In press.

31. Casalino LP, Devers KJ, Lake TK, Reed M, Stoddard JJ. Benefits of and barriers to large medical group practice in the United States. Arch Intern Med 2003;163:1958-64.
32. AAFP. Practice profile of family physicians, 2006. www.aafp.org/online/en/home/aboutus/specialty/ facts/4.printerview.html.

33. O'Connor PJ. Electronic medical records and diabetes care improvement: are we waiting for Godot? Diabetes Care 2003;26:942-3.

34. Crosson J, Ohman Strickland P, Hahn K, et al. Use of electronic medical records is associated with lower quality diabetes care in primary care practices. Ann Fam Med. In press.

35. Vanmeerbeek M. Exploitation of electronic medical records data in primary health care. Resistances and solutions. Study in eight Walloon health care centres. Studies in Health Technology and Informatics 2004;110:42-8.

36. O'Connor PJ, Crain AL, Rush WA, Sperl-Hillen JM, Gutenkauf JJ, Duncan JE. Impact of an electronic medical record on diabetes quality of care. Ann Fam Med 2005;3:300-6.

37. Reiber GE, Boyko EJ. Diabetes research in the Department of Veterans Affairs. Diabetes Care 2004;27 Suppl 2:B95-8.

38. Edmondson AC. Framing for learning: lessons in successful technology implementation. Calif Manage Rev 2003;45:34-54.

39. Edmondson AC, Bohmer RM, Pisano GP. Disrupted routines: team learning and new technology implementation in hospitals. Adm Sci Q 2001;46: 685-716.

40. Sandars J. Knowledge management: something old, something new! Work Based Learning in Primary Care 2004;2:9-17.

41. Sandars J. Knowledge management: we've only just begun! Work Based Learning in Primary Care 2004; 2: 208-13.

42. McElroy M, Firestone J. The Partners HealthCare case for improved KM. KM Review 2005;8:6-7.

43. Lyles MA, Easterby-Smith M. Organizational learning and knowledge management: agendas for future research. In: Blackwell handbook of organizational learning and knowledge management. New York: Oxford University Press; 2003. p. 639-52.

44. Nonaka I, Takeuchi H. The knowledge-creating company: how Japanese companies create the dynamics of innovation. New York: Oxford University Press; 1995.

45. Rushmer R, Kelly D, Lough M, Wilkinson JE, Davies HT. Introducing the learning practice-I. The characteristics of learning organizations in primary care.[see comment]. J Eval Clin Pract 2004;10:375-86. 